of serious and fatal cases occurring amongst patients beyond the age of fifty years.

Kænig distinguishes two principal forms of intoxication-the light form and the grave.

In the light form the patients experience anorexia, headache, loss of memory; they appear morose, or even delirious, cry without reason, and seem fearful of being persecuted. The pulse becomes enormously accelerated-the temperature perhaps slightly elevated. Symptoms subside within a few days, recovery taking place.

In the grave form hallucinations of variable nature occur; sometimes delirium assumes a furious character, or the patient becomes terror-stricken, and may even exhibit a disposition to commit suicide. Food is refused; urinary secretion becomes scanty; the pulse is rapid; the temperature rises to perhaps $104^{\circ} \mathrm{F}$.; the dénouement is almost always fatal, the patient dying in a state of coma.

Young subjects generally present symptoms resembling those of meningitis, but usually without elevation of temperature.

Kænig and Aschenbrandt have, like Martin, observed, at post mortem examinations, evidences of iodoform-pneumonia.

I think few surgeons will be found to oppose the recommendations of Martin and Veliaminoff, that iodoform should, in all cases where its use is indicated, be applied in small quantity; that especial caution should attend its use when much adipose tissue is exposed, and when the wound is extensive; that its employment is more or less contra-indicated by advanced age, tendency to fatty degenerations, diseased conditions of heart or lungs, and when there exists a susceptible condition of the nerve centres.

ArT. VI.-The Morbid Anatomy of Diabetes Mellitus. ${ }^{\text {By }}$ Bertram C. A. Windee, M.A., M.D. (Dubl.); Pathologist to the General Hospital, Birmingham.

There is, perhaps, no other disease whose morbid anatomy has been so carefully explored, with so small practical results, as diabetes mellitus. Quite recently interest has been re-awakened in the subject, and a determined effort made to discover the secret of its pathology. In this paper I have endeavoured to embody, as far as possible in a tabulated form, the records of such autopsies on cases of this disease as $I$ have been able to discover.

a Being a Thesis for the Degree of M.D. in the University of Dublin. 
To these, by the kindness of the medical committee, I have been enabled to add the accounts of some examinations from the post mortem records of the General Hospital, Birmingham.

On glancing over the tables a fact, which must have already struck many, will at once become evident-viz., the extraordinary diversity of the lesions described in connexion with this disease. To this fact, and the deductions from it, I purpose returning later. I may as well state here that $I$ am not in a position to advance any theory as to the pathology of diabetes mellitus, nor has such been my purpose in this paper. My object has been, if possible, to lay a foundation of cases which may possibly facilitate further work.

Without more remarks I will pass to the consideration of the lesions found in the various organs.

Brain.-The condition of this organ has been noted in 184 cases which $I$ have found records of, with the following results :-

TABLE I._Brain. No. of Cases, 184.

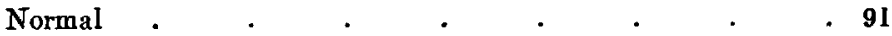

Excavations around arteries, beginning usually in hæmorrhages ${ }^{\mathrm{a}} \mathrm{ll}$

$\begin{array}{lll}\text { Enlarged perivascular sheaths of vessels (generally only slight) } & 8\end{array}$

Congestion of capillaries and degeneration of nerve cells in floor of fourth ventricle

Tumours in fourth ventricle $\quad$. $\quad . \quad$. $\quad . \quad 4$

Hyperæmia $\quad$. $\quad$. $\quad$. . . . 4

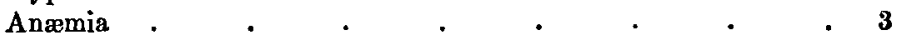

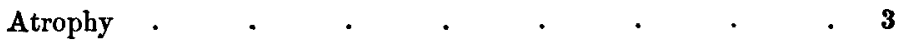

Cerebral hæmorrhage.$\quad$. $\quad$. $\quad$. 3

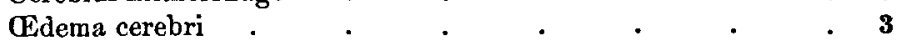

Puncta cruenta unusually numerous . . . . . 3

Increase of sub-arachnoid fluid . $\quad . \quad$. $\quad$. $\quad$. 3

Hyperamia and fatty degeneration of floor of fourth ventricle . 2

Extravasations on floor of fourth ventricle $\quad$. $\quad . \quad 2$

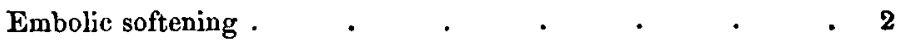

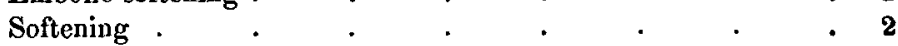

Hyaline thickening of coats of arteries . . . . 2

Disseminated sclerosis . . . . . . . 1

Edema of membranes . $\quad$. $\quad$. $\quad$. $\quad . \quad$. 1

Softening and hyperæmia. $\quad . \quad$. $\quad . \quad$. $\quad$. 1

Hypertrophy and anæmia $\quad . \quad$. $\quad . \quad$. $\quad$. 1

Tough . $\quad . \quad$. $\quad . \quad$. $\quad$. 1

Hard nodule in right middle lobe, with capillary extravasations ${ }^{\prime} \quad l$

Suppuration at anterior inferior portion of right anterior lobe ${ }^{b}$ I

- Dickinson.

D After fracture of skull 
Softening of cerebellum and left middle peduncle $e^{z}$. $\quad$. 1 Meningitis . $\quad . \quad \cdot \quad \cdot \quad . \quad . \quad . \quad 1$

"Tumour" (situation not mentioned) . . . . . . 1

Hæmorrhage over base, extending to medulla oblongata . I

Almost entire disappearance of gray matter at level of fourth ventricle

Softening of pons ; induration of medulla oblongata ; atrophy of

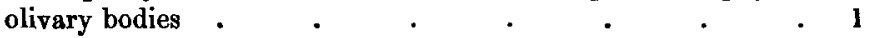

Softening and atrophy of medulla oblongata, with diminution of

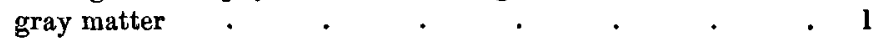

Hydrocephalus . $\quad . \quad$. $\quad . \quad$. $\quad . \quad$. $\quad . \quad 1$

Tubercle . $\quad . \quad$. $\quad . \quad$. $\quad . \quad . \quad . \quad 1$

Sarcoma of right balf of medulla oblongata $\quad$. $\quad$. I

Induration and extravasations of blood in posterior part of right half of medulla oblongata

Ossific growth pressing on pons, with abscess in posterior cerebral lobes . $\quad . \quad . \quad . \quad . \quad . \quad . \quad 1$

Tumour on inferior surface of medulla oblongata $\quad . \quad$. 1

Point of softening at bottom of fourth ventricle . . . . 1

Vessels at base of brain diseased (? nature) . . . . . 1

Blood clot in medulla oblongata and pons . . . . 1

Clot over right hemisphere $\quad$. $\quad . \quad$. $\quad . \quad$. 1

Small cavity, with whey-like and fibrous contents between left thalamus opticus and corpus striatum, eight similar ones on

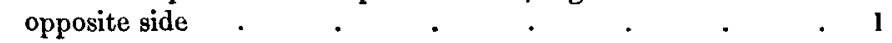

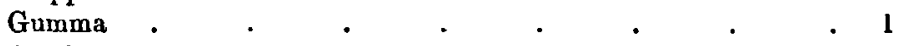

Cysticercus $\quad . \quad$. $\quad . \quad$. $\quad . \quad$.

Meningitis acuta purulenta $\quad$. $\quad$. $\quad$. $\quad$. $\quad$. 1

Thrombosis of sinuses ${ }^{b} \quad$. $\quad . \quad$. $\quad . \quad$. $\quad . \quad$. 1

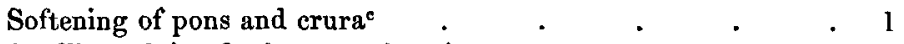

Swelling of tip of calamus scriptorius $\quad . \quad$. $\quad \cdot \quad \cdot \quad \cdot \quad l$

Colloid-like bodies in medulla oblongata and cerebellum . 1

The curious diversity of the lesions found in the brain is more marked than in the case of any other organ. Nevertheless, as will be seen from the preceding table, in almost exactly one-half of the cases described, no change was discovered. Of course a number of these brains were not examined microscopically, and therefore it may be a question whether they were really normal. But, on the other hand, a number were most carefully examined by competent pathologists, without the slightest deviation from the normal being discovered. There can be no disputing this fact, and it proves either that the seat of the disease is not in the brain, or that the change which produces it is one which, up to the present, has

- After fracture of occipital bone.

- Following caries of petrous portion of temporal bone.

- Syphilitic stenosis and thrombosis of basal arteries. 
eluded all attempts at discovery. The important discovery of Cl. Bernard, in connexion with the artificial production of glycosuria, lends an additional interest to all lesions connected with the medulla oblongata and fourth ventricle. Of these twenty-three will be found in the table, yet it is a significant fact that no one of these changes was seen in more than four cases. When saying this, exception must be made in the case of the series of changes described by Dr. Dickinson, ${ }^{\mathrm{a}}$ which are too well known to need further mention. Since the appearance of his first paper, very careful search has been made in a number of instances for the lesions described by him, but the result has not altogether been to corroborate his statements. I have most carefully examined myself three brains and spinal cords with negative results. Again, these changes, said to be characteristic of diabetes, have been found in the brains of persons not the subjects of the disease. It seems probable that the method of preparation adopted-viz., that of hardening in chromic acid, may account for some of the appearances, as the tendency of this substance is to shrivel up tissues, more than is the case with other fluids. At the same time, it is only fair to say that these changes are not the necessary sequela of such a method of preparation-one amongst Frerichs' cases $^{b}$ is an instance in point. An interesting series of cases are those in which glycosuria has followed an injury, usually of the head. Two such cases, where cerebral lesions were discovered post mortem, are included in the table. In the paper from which they were taken, ${ }^{\mathfrak{c}}$ in which there are collected a number of such cases, one other is mentioned where diabetes followed a fracture of the occipital bone and basis cranii, but the brain itself was quite normal.

TaBLe II.-Spinal Cord. No. of Cases, 58.

Normal $\dot{\text { Excavations around vessels, with sometimes dilatation of central }}$ canal . . . . . . . . . . 11

Hyaline thickening of coats of vessels $\quad$. . . . 2

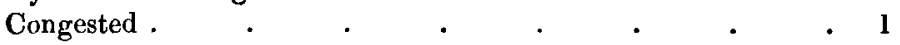

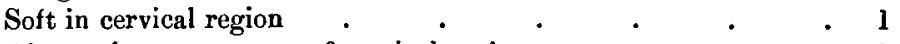

Abscess in gray matter of cervical region. $\quad . \quad$. $\quad . \quad 1$

"Posterior columns changed" (? nature). . . . . 1

"Cord diseased" (nature of disease not specified) . . . 1

"Med. Chir. Trans., 1870, p. 238, et seq. ; and Diabetes, 1877.

b Plötzliche Tod und Coma bei Diabetes. Zeitschrift für klinische Medicin. Bd. 6, Heft 1, p. 10. No. 7.

c Arch. Gen. de Médecine, 1862, v. 2. 
Congestion of vessels and clot beside cord at $3 \mathrm{rd}, 4 \mathrm{th}$, and 5 th dorsal nerves; softening of cord there, and at 3rd and 4th cervical nerves Myxoma of dura mater, with changes in cord, including proliferation of epithelium in central canal, and sponginess of gray matter".

Old disintegration of gray matter at 7 th cervical vertebra ${ }^{b} \quad$. 1

In connexion with the spinal cord there are some cases of glycosuria following injuries to the vertebral column. In one cited in the paper before mentioned dislocation of the vertebral column was followed by diabetes, but no lesion was discovered in the cord post mortem.

TABLE III._Ganglia of Sympathetic. No. of Cases, 17.

Normal

Increase in connective tissue; thickening in capsules of cells; diminution of cells, and of medullated fibres in ganglia $\quad 5$

Hyaloid thickening of coats of vessels . $\quad . \quad$. $\quad 2$

Pinkness of some when compared with others . . . . 1

Small

It is rather surprising how little attention has been bestowed on these most important organs. Poniklo's are, so far as I am aware, the only observations, up to the present, of much importance. In one of his cases, besides the changes mentioned above, he found dilatation of the blood-vessels; in another, pigmentation of the cells.

Before leaving the nervous system, it may be mentioned that tumours have been found in two cases pressing on the vagus.

TABLE IV.-Heart. No. of Cases, 94.

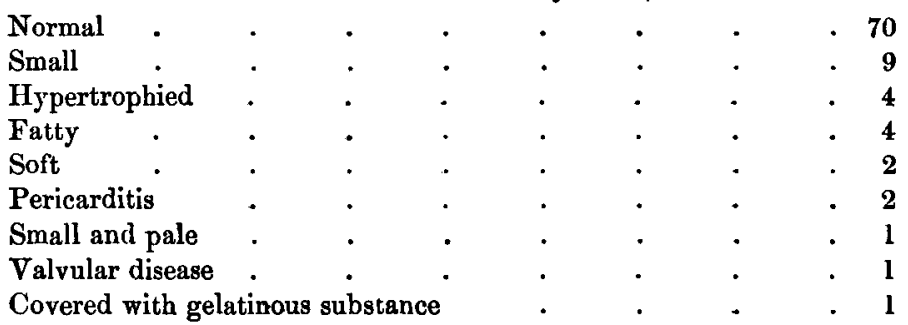

Under this heading may also be mentioned the changes described in the arteries by Dupuytren, ${ }^{\mathrm{c}}$ Lécorché, ${ }^{\mathrm{d}}$ and others. They are

"Smith. Brit. Med. Jour., April, 1883. P. 657.

b Glycosuria appeared fiftoen days after fracture of the 7 th cervical vertebra. Death in two years from phthisis.

c Dupuytren. Dict. de Méd. et Chir. Pratiques (fide Lécorehé).

d Lécorché. Traité du Diabète. 
of a fatty and atheromatous nature, attack most frequently the small arteries of the brain and its membranes, and often those of the retina. The large arteries seem generally to escape. Lately hyaloid thickening of the coats of the small arteries in various organs has also been described. The condition of the blood may also be alluded to here. In some cases it has a pink, "strawberryice" appearance, and on being allowed to stand, the serum collecting on the surface is milky white from the presence of quantities of free fat. This condition is met with, however, in a comparatively small number of the cases recorded, and as it occurs, according to Hertz, ${ }^{a}$ in pneumonia and in drunkards, cannot be considered as peculiar to diabetes.

TaBLe V._Lungs. No. of Cases, 333.

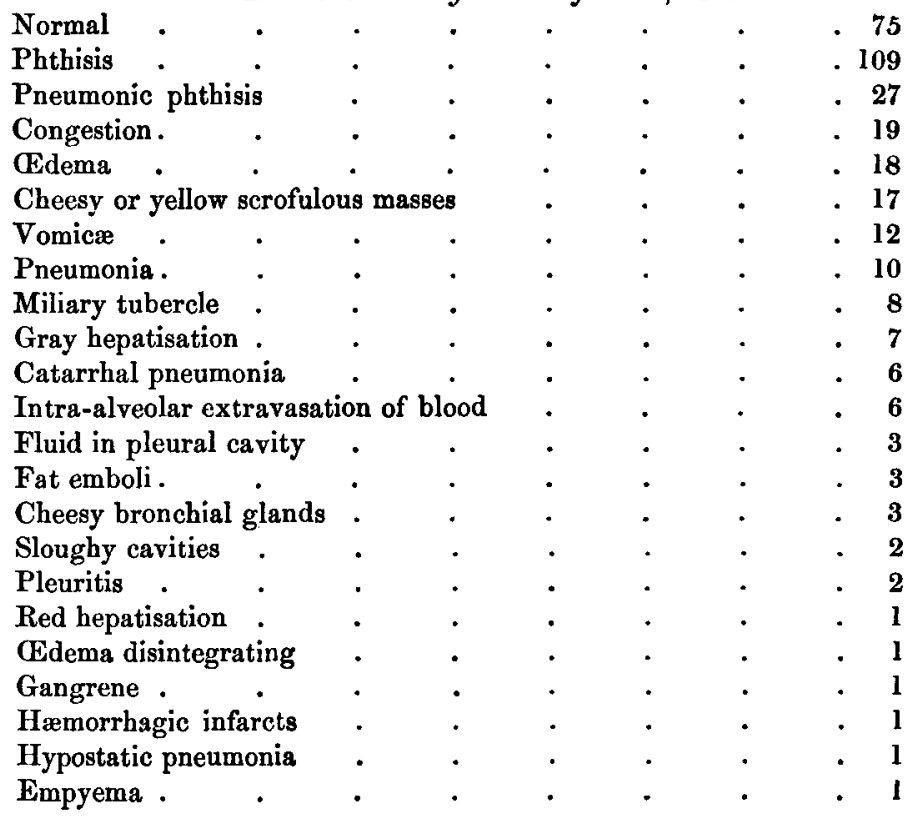

It has long been a well-recognised fact that a very large number of the fatal cases of diabetes presented, on post mortem examination, the appearances of the disease, or group of diseases, known as phthisis. By referring to the table above it will be seen that out of a large number of cases rather more than one half presented these changes. About their nature there has been much debate; but the general opinion seems to be that they are

- Deutsch. med. Woch., 1881, No. 27 (fide Saundby and Barling, loc. inf. cit.). 
not tubercular in the strict sense of the word. Addison described the change as "albuminisation." It has been variously ascribed to the contact of saccharine blood and to nervous influence. The latter opinion seems by far the more probable, supported as it is by the evidence of direct experiment. An account of some of these experiments will be found in Dr. Dickinson's work. ${ }^{a}$ In connexion with this point I may call attention to the fact that Dr. T. E. Little has pointed out that lesions affecting the pneumogastric are a cause of certain forms of phthisis. The facts brought out in his papers on this subject lend additional support to the theory of nervous influence. The recent discoveries in connexion with the bacillus of tubercle form a new starting point for the investigation of the nature of these lesions. As yet, however, little has been done in this direction. Dr. Stephen Mackenzie ${ }^{c}$ has examined four cases for bacilli with negative results. I have myself examined only one well-marked case, and in this I failed to find any.

The subject of fat embolism of the lung may here be alluded to. Professors Sanders and Hamilton ${ }^{d}$ were the first to describe this lesion in a case of diabetes dying comatose with fatty blood. Since the appearance of their paper two other cases have been reported of a similar nature in which a few fat embola were discovered. In other cases a careful search has failed to discover any. In two cases of diabetic coma which came under my notice I discovered none. It is true that the blood was not milky in either of these. It seems doubtful whether the appearances described by Sanders and Hamilton were fat embola at all. In a paper by Dr. Saundby and Mr. Barlingf it is pointed out that " these so-called fat embola are mere post mortem thrombi with fat globules embedded in them," and the facts adduced by these authors seem fully to bear out their conclusion.

TABLE VI._Liver. No. of Cases, 220.

\begin{tabular}{|c|c|c|c|c|c|c|c|}
\hline Normal & . & • & • & . & • & • & \\
\hline Enlarged & . & . & . & . & • & • & . \\
\hline$"$ & and congested & • & • & • & • & • & - \\
\hline Congested & 1 & . & . & - & . & • & . \\
\hline
\end{tabular}

b Irish Hospital Gazette, April 15, 1874 ; and Proc. Dub. Univ. Biol. Assoc., Vol. II., No. 2, p. 25.

- Brit. Med. Journ., April 7, 1883, p. 666.

d Edin. Med. Journ., July, 1879.

- Starr.-New York Med. Rec., May 1, 1880. Fitz.-Boston Med. \& Surg. Journ., Feb., 10, 1881.

'Journ. of Anat. \& Phys. Vol. XVI., pp. 522-524. 


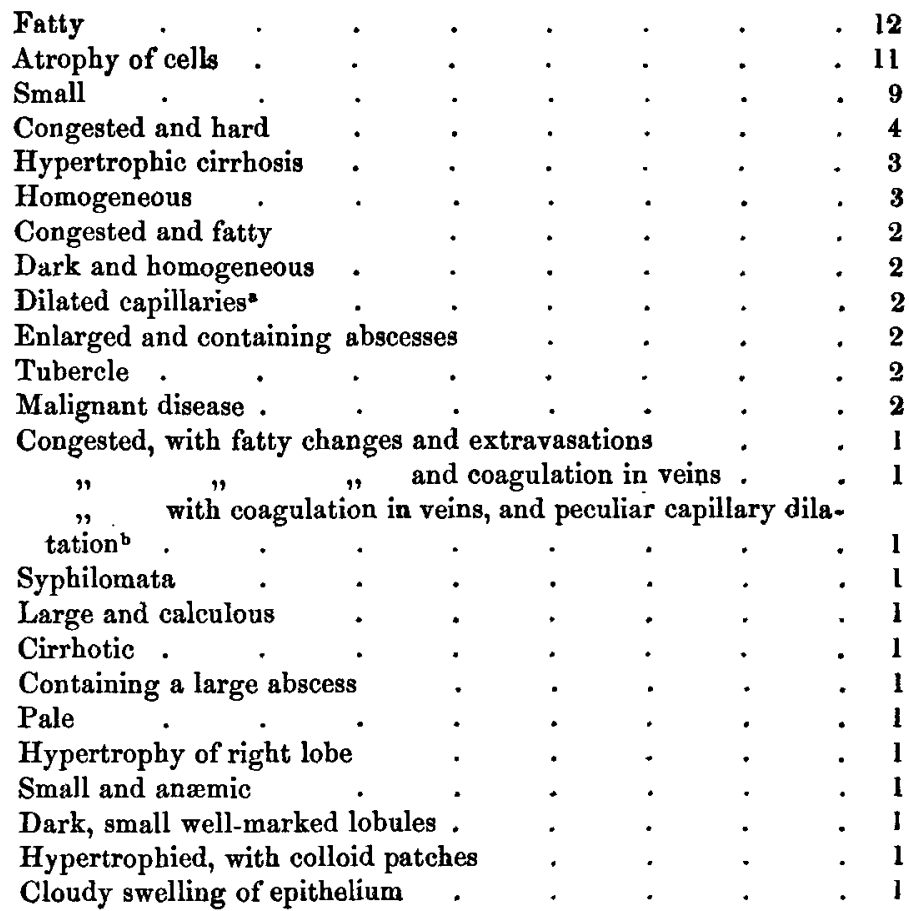

The most common change recorded, as will be seen from the above, is enlargement with or without congestion. Careful microscopical examination has failed to discover that change in the organ which from physiological data we might be led to expect. According to some authors there is a proliferation of the hepatic cells, and Rindfleisch considers that this is limited to those in the periphery of the lobule which are most closely connected with the portal system. Other observers have not, however, confirmed these statements. Dr. Wilks considers that the appearance of the diabetic liver is quite characteristic, being firm, tough, homogeneous, or uniform in appearance, and dark in colour. In connexion with this organ it is interesting to note that in animals affected with diabetes, the most common lesion is fatty degeneration of the liver. Next to this comes atrophy of glands, especially the testes and ovaries. Lesions of the kidney are rare, whilst the only cerebral change recorded is steatosis and softening of the pituitary body,

In one.case the seats of these dilatations were depressed. Frerichs. Op. sup. cit., No. 12.

b Dickinson. Op. supra cit. 
which was once observed in a $\operatorname{dog}$ the subject of this disease. Finally, Dr. Stephen Mackenzie considers a shiny homogeneous condition of the liver and spleen as the next most common post mortem appearances to the phthisical changes already alluded to. ${ }^{b}$ Pavy states that the bile usually resembles rhubarb mixture. In two cases, both ending by coma, which I have seen, the gall bladder was once empty, and once contained about $m$ xx. of normal bile. In a third case there was no abnormality observed.

TABuE VII._Spleen. No. of Cases, 95.

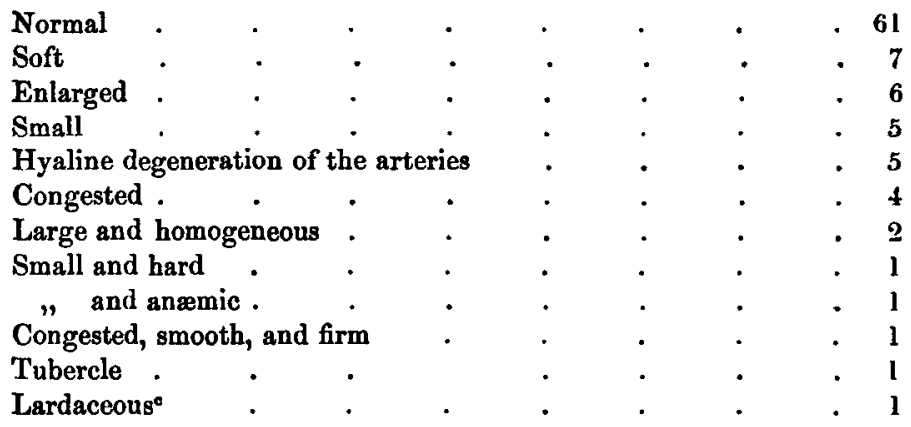

In one of two cases which $I$ have examined $I$ have been unable to find the hyaline degeneration of the arteries which has recently been described as constant in this organ. It was present to a small degree in the other case. Dr. S. Mackenzie's statement has already been quoted under the heading of the liver.

TABLE VIII.-Kidneys. No. of Cases, 271.

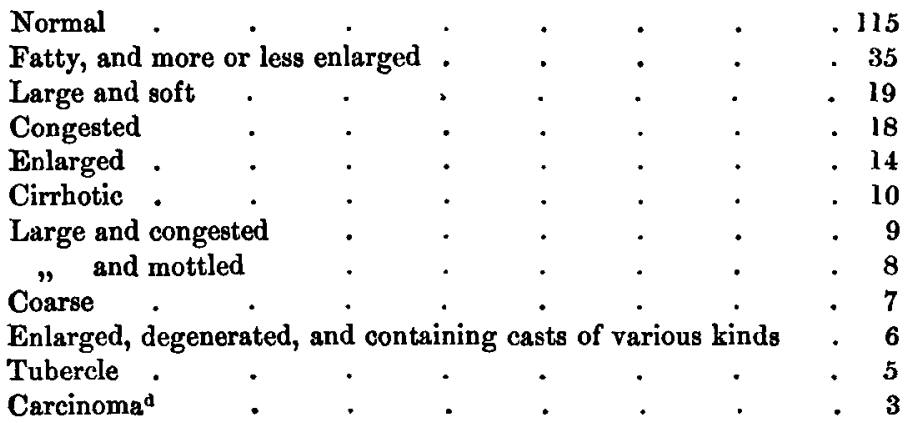

- Revue Vétérinaire for 1870-71-72. Arch. Gén. de Méd., Vol II. for 1873.

b Brit. Med. Journ. Supra cit.

- History of old syphilis.

a Rokitangki (teste Lécorch6). This is not mentioned in Seegen's account of Rokitanski's autopsies. 


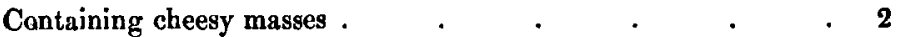

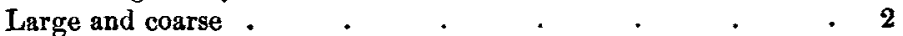

Anæmic . . . . . . . . 2

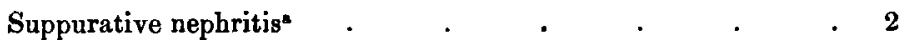

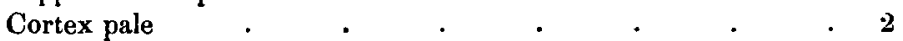

Cloudy swelling of epithelium $\quad . \quad$. $\quad . \quad$. $\quad . \quad 2$

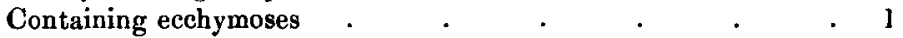

Calculous Pyelitis . $\quad . \quad$. $\quad$. $\quad . \quad$. $\quad .1$

Enlarged, pale, with purulent foci $\quad$ - $\quad . \quad$. $\quad . \quad 1$

Enlarged, firm, anæmic, with dilated pelves . . . . I

Diminished cortex.$\quad$. $\quad . \quad$. $\quad . \quad$. 1

Scrofulous nephritis $\quad . \quad$. $\quad . \quad$. $\quad . \quad$. 1

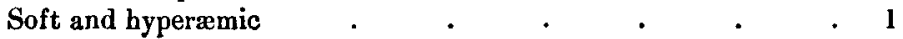

Softening of cortex

The enlargement of the kidney, which is so frequently met with, is to be expected in an organ whose duties are so much augmented. For some time the enlargement was almost the only feature noted, save Prout's observation that the diabetic kidney exposed to the air became of an orange colour. Of late much more attention has been devoted to its internal structure. According to Ebstein, necrosis of the epithelium of the tubes, and hyaline degeneration of Henle's loop, ${ }^{b}$ are to be discovered. To the former of these statements more recent observers take exception, Frerichs ${ }^{\circ}$ considering that Ebstein's appearances are mainly due to the use of imperfect re-agents. On the other hand, in an appendix d to Frerichs' paper it is shown that in all cases of diabetes glycogen may be found deposited in the epithelium of Henle's loop. Sanders and Hamilton found fat emboli in one case; this has, however, been already spoken of under the heading of the lungs. I have examined four kidneys microscopically-one of these was normal; two showed extensive fatty degeneration; in the fourth the epithelium was granular and swollen, especially in the convoluted tubes. In some tubes were masses of broken-down epithelium; in others granular débris; others, again, contained blood corpuscles, and in a few there were bodies somewhat resembling hyaline casts; but though possessing their solid appearance, they lacked their

- In one case following stricture of urethra.

b Ebstein. Deutsche's Archiv. Bd. 24 (vide Frerichs).

c Op. sup. cit. Pp. 30-31, note 2.

a Op. sup. cit. Anhang i. "Ueber das Vorkommen von Glykogen im diabetischen und im normalen Organismus." Bg Prof. Dr, Ehrlich. 
translucency, and were more granular. ${ }^{2}$ I did not examine any of them for glycogen.

TABLE IX.-Pancreas. No. of Cases, 139.

\begin{tabular}{|c|c|c|c|c|c|}
\hline Normal & & - & . & - & \\
\hline Atrophied & & & & . & \\
\hline with fatty deg & eneratio & $n$ of & & - & \\
\hline Changed to fibrous band & & • & - & - & . \\
\hline Atrophy from calculi in $d$ & & . & . & . & \\
\hline Malignant disease . & & . & $\cdot$ & . & \\
\hline Cloudy swelling of epithe & ium & . & . & . & \\
\hline Calculi in duct, without a & trophy & . & . & . & \\
\hline Fatty & . & . & . & . & \\
\hline Large and fatty ${ }^{b}$. & • & . & . & $\cdot$ & \\
\hline Soft & $\cdot$ & . & . & • & \\
\hline Congested. & 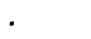 & . & . & . & \\
\hline Small well-marked lobule & & . & - & . & \\
\hline Transformed to cystic po & & . & . & . & \\
\hline Fatty, with dilated ducts & . & . & . & ${ }^{\circ}$ & \\
\hline Dark coffee-brown ${ }^{e}$ & $\bullet$ & . & • & $\cdot$ & \\
\hline Small hæmorrhages & . & . & . & . & \\
\hline Cretaceous. & . & 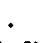 & . & & \\
\hline "Changed" (alteration & 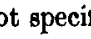 & ied) & & & \\
\hline
\end{tabular}

It will be seen from the above that in rather more than half the cases recorded the pancreas has undergone change. In the majority of cases this tends in the direction of atrophy, which ranges in degree from a mere diminution in bulk, through the stages of cirrhosis, to the extreme condition of complete degeneration into a fibrous band. However, we must not forget that almost identical lesions of this organ may be found in two cases, in one of which glycosuria is present, in the other absent. Instances will be found in Bright's paper ${ }^{d}$ on disease of the pancreas, accompanied by fatty stools. It is curious to note that this symptom also is present in some cases of pancreatic disease-absent in others apparently precisely similar. I have examined microscopically four specimens. In two there was cloudy swelling of the epithelium; in both these cases the organ was smaller than normal, and both terminated by coma. In a third case, also terminating by coma, with milky blood, the pancreas was small and hard, and a section showed a quantity of fibrous tissue surrounding fatty and degenerated epithelium. In the fourth case the organ was

arit. Med. Jour., May 12, 1883.

b Doubtful fat. Glands in neighbourhood rather choesy.

c Salivary, mesenteric, and retro-peritoneal glands similarly affected.

d Med. Chir. Trans. Vol. XVIIL, p. 3. 
represented by a fibrous band, and microscopic examination failed to show any trace of its normal constituents.

Table X._Stomach. No. of Cases, 77.

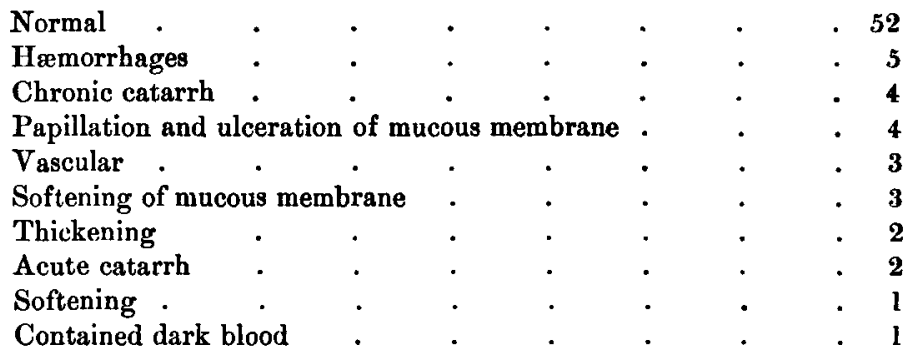

Thickening of the mucous membrane, though only mentioned twice above, because in those cases it was the sole lesion, was found in several of the other autopsies as an accompaniment of some other change. A condition of distension with gas appears to be also very common.

TABLE XI.-Intestines. No. of Cases, 69.

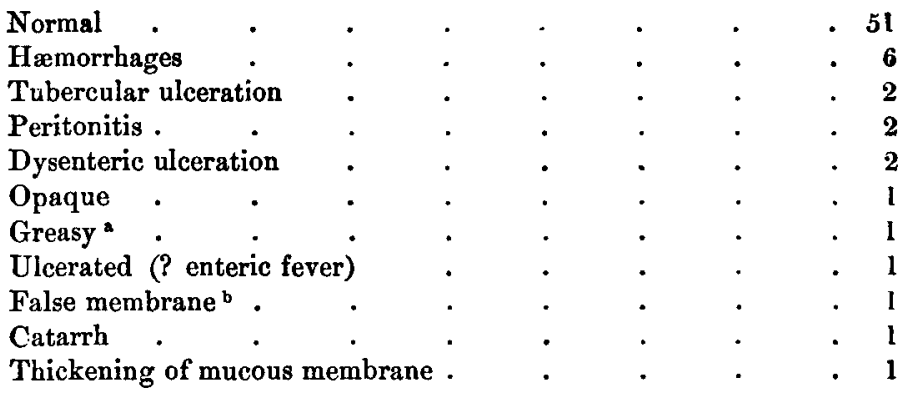

In two cases which came under my notice, both of which terminated by coma, large masses of tænia medio-canellata were found in the intestines. This fact may have more importance than at first sight appears to be the case, when we take into consideration the influence of the larger entozoa on the cerebro-spinal system. ${ }^{\circ}$ After the injection of acetone into guinea-pigs, the following lesions were found constantly:-Hæmorrhages in pleura, a pale liver, acute fatty degeneration of the cortex of the kidney,

- Disease of pancreas ; fatty stools.

b In large only ; small, normal.

c Cf. passim. Heslop. On the Cerebro-spinal Symptomatology of Worms, especially Tape-worms. Dub. Quarterly Jour. of Med. Sci. Vol. XXVII., p. 275 ; and Vol. XXVIII., p. 133. 
the mucous membrane of the duodenum thickened and rose-colour, and that part of the intestine distended with a paste consisting of serum and epithelium. These lesions should be remembered when weighing the value of the acetonæmic theory of diabetic coma. In one case of coma I found sub-pleural and diaphragmatic hæmorrhages, and a small amount of bloody fluid in the pelvis, together with very numerous extravasations in the duodenum, becoming fewer, and finally ceasing in the jejunum. I did not observe any marked detachment of the epithelium in the alimentary canal, though it was desquamated from the bladder and vagina in excessive quantities, some of the flakes in the urine consisting of as many as forty cells.

TABLE XII._Bladder. No. of Cases, 40.

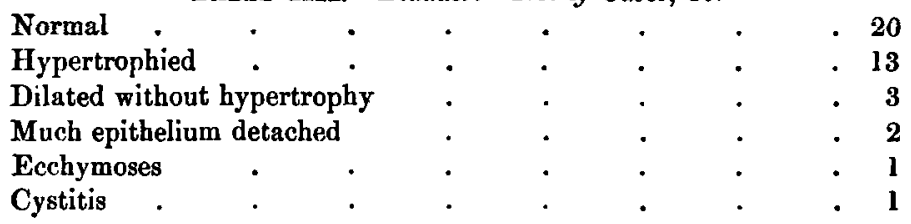

The hypertrophy so frequently met with in this organ can, of course, be explained on mechanical principles. With regard to other organs, the supra-renals have been recorded as enlarged in one case. I have not found any change macroscopically or microscopically in my cases. The ovaries have been described as atrophied in some cases, cystic in others. The following lesions require only passing mention:-Cataract, diseases of gums, alveoli and teeth, and carbuncles.

After reviewing the tables given above, one fact is most especially impressed upon us, and it is this-that we are not justified, from our present knowledge, in drawing any definite conclusion as to the pathogeny of diabetes.

Before we can do this it will be necessary to have records of a number of cases carefully tabulated as to the following particulars at least-cause, duration, mode of death, and posi mortem appearances. As regards these last, as far as naked-eye appearances go, the line has been nearly worked out.

The discrepancies which are so marked a feature in the record of autopsies go to prove that most careful microscopic examinations of all the organs afford the only hope of detecting the characteristic lesion of this disease.

- Thudichum. Arch. of Chem. Med. Vol II. "Diabetic Coma." 
At present the position seems to be nearly this-either diabetes is a distinct disease, or it is not. In the former case we can scarcely believe that it has not some definite lesion, which up to the present has certainly not been discovered. If the latter hypothesis be true, we must learn to look upon it in the same light as jaundice, as a symptom which may be due to various causes and lesions.

Finally, it may appear that my tables are too prolix, and that the same condition is sometimes entered under two or more slightly different headings. My object, however, was to give the words of my authorities, leaving anyone who may see this paper to draw his own conclusions from it.

\section{MALARIAL LARYNGITIS.}

Dr. E. BRIAND having seen certain cases of false croup of no other than malarial origin, concludes that: 1 . There exists a form of laryngitis due to malaria, characterised by congestion of the larynx, giving rise, from a symptomatic point of view, to the functional signs of true croup. 2. This variety of laryngitis differs from laryngismus stridulus by the symptoms, course, and prognosis, and generally yields to treatment by sulphate of quinine. 3. It is not very rare in infants, and may be recognised by the fact that it is preceded or followed by malarial manifestations.-Revue Méd. Franç. et Étrang., May 26, 1883; and Medical News, July 7, 1883.

\section{a Colony OF ascarides as a CaUSe of DEath.}

Dr. Egeberg (Norsk Magaz. f. Lagevid., Third Series, Vol. XII, "Proceedings of the Norwegian Medical Society," and Nordiskt med. Arkiv., Vol. XV., Part I., 1883) exhibited before the Norwegian Medical Society, a portion of intestine from a girl aged four years, who, when two years old had discharged a lumbricus in a bloody motion from the bowels. She had subsequently been healthy, except that off and on she had transitory pains in the abdomen. On the evening of the 11th of February she was attacked with violent pains in the stomach and incessant vomiting, but there was no evacuation of the bowels; she became collapsed, and died next morning, twelve hours after the occurrence of the first symptoms. At the antopsy evidences of peritonitis were discovered, and the terminal portion of the small intestine for about eighteen inches upwards from the valve of Bauhin (ileo-cæcal valve) was completely crammed with lumbrici. No other cause for the peritonitis could be detected. 